\title{
BROWN STAIN AND ITS EFFECT ON THE STRENGTH OF PINE POLES ${ }^{1}$ \\ BY C. W. FRITz 2 \\ IN'TRODUCTION
}

A chocolate brown stain frequently develops in the sapwood of red pine and jack pine poles during storage under warm, humid conditions; it is one of the many discolorations caused by the growth of fungi in sapwood. Blue stain, which ranges from light grey-blue to almost black, is the most prevalent and widely known sapwood discoloration; owing to the spectacular rapidity with which it may develop in lumber in the seasoning yard, and the resultant serious monetary losses which may ensue, intensive study has been given to establishing methods of preventing its development. Other fungal discolorations, however, including shades of yellow, orange, pink, brown, etc., may be equally disfiguring; if extensively developed, as often happens in the case of brown stain, these may cause serious de-grade.

This dark brown stain is so conspicuous and unsightly (Fig. 1), that in recent years users of pine poles have become increasingly concerned as to its cause and its effect on the strength of the wood. A few years ago nine red pine poles, graded as containing light, medium, or heavy brown stain, were tested for strength at the Ottawa Laboratory of the Forest Products Laboratories Division; the results showed that variation in strength was not related to the intensity or distribution of the brown discoloration.

Samples submitted for pathological study were subjected to cultural analysis. The wood presented a mottled appearance, which suggested the presence of more than one fungus; cultures were, therefore, made from points representative of the various colours. Dark brown areas yielded a fungus which produced a brown mat on malt agar, and stained the medium an intense dark brown to black; from areas lighter in colour fungi of the type associated with wood rots were obtained. The problem presented was to relate these fungi to brown stain and to mechanical properties; to that end it was necessary to study the effect of each fungus individually on the wood.

\section{Cause}

\section{BROWN STAIN}

It seemed logical to expect that the fungus which produced a brown mat and coloured malt agar a dark brown might be responsible for the production of similar discoloration in the wood. Sterilized chips of red pine sapwood were placed on growing mats of the fungus; these became infected in a few days, and soon showed the characteristic brown discoloration. Small sticks were then inoculated under aseptic conditions and incubated at $27^{\circ} \mathrm{C}$. until good growth was obtained. The fungus readily penetrated and stained the wood; it was then reisolated on malt agar, on which it produced mats similar to those originally obtained from the

1 A contribrition of the Forest Products Laboratories Division, Forestry Branch, Department 2 Wood Pathologist 
naturally stained wood. These tests established this fungus as the cause of chocolate brown sapwood stain. After a few weeks growth on wood in culture, the fungus sporulated on the surface of the blocks, and was identified as a species of Cytospora.

\section{Effect on Strength}

Having found the cause of brown stain, there remained the determination of its effect on the strength of the wood. For this purpose it was decided to subject stained specimens to static bending and toughness tests, for which sticks measuring $2 \mathrm{~cm} . \times 2 \mathrm{~cm}$. x $32 \mathrm{~cm}$. would be required. To stain sticks of this length uniformly, inoculum which can be distributed evenly over a longitudinal surface is required. Since the brown stain fungus does not sporulate readily in culture, it was necessary to produce a suitable suspension of mycelium. Mats of the fungus were grown on malt agar plates and minced in a Waring blendor. All tests were conducted under strictly aseptic conditions. After several trials it was concluded that mincing a ten-day old mat for one minute in $100 \mathrm{cc}$. sterilized distilled water provided a viable suspension, sufficiently fine to be delivered by the pipettes used for transferring.

A tube was then designed to accommodate the test stick and to hold it in position suitable for the growth of the fungus. The tube adopted, with stick in position for inoculation, is shown in Fig. 2; it measures 45 $\mathrm{cm}$. in length and has an inside diameter of $6.4 \mathrm{~cm}$. The stick lies on two horizontal rests formed by indentations of the wall, the rest toward the mouth being closed across the tube to prevent water from reaching the plug, and that at the closed end open to allow water to flow to the end of the tube. The stick is held in a central position and away from the end of the tube by indentations in the walls; there is space below the stick to accommodate water freed from the wood during sterilization, and space above to permit the insertion of the long pipette used to apply inoculum over the length of the stick.

After preliminary trials on a few samples to establish a satisfactory technique, two series of specimens were prepared, one for static bending and the other for the toughness test. To provide the test sticks, sapwood from a freshly felled red pine log was converted to strips, $2 \mathrm{~cm} . \times 2 \mathrm{~cm}$. in cross section, each oriented to provide radial and tangential surfaces. From these, fifty-two end-matched groups of three samples were obtained, each sample measuring $32 \mathrm{~cm}$. in length; twenty-nine groups were used for static bending, and twenty-three for the toughness test. Two sticks of each group were sterilized in tubes as shown in Fig. 2. The sticks in all cases were oriented to provide a tangential face uppermost for inoculation. One stick was inoculated with a standard suspension of $C y$ tospora; both were incubated at $27^{\circ} \mathrm{C}$. until satisfactory stain developed in the inoculated stick. The third stick was used as a green control and immediately subjected to the appropriate mechanical test.

The sticks were incubated for nine to eleven weeks and tested immediately after removal from the tubes. As soon as the sticks were tested for 
strength, a 3-inch piece was cut from one end of each for moisture content determination. To establish the purity of the growth of Cytospora and the presence of the fungus in the area of test, four cultures were then made from each stick, two from each side of the load point. The specimens were then ripped to show the extent to which the fungus had penetrated.

Satisfactory staining had developed in the sticks (Fig. 3), but the results of the strength tests were somewhat surprising in that they suggested in some respects a slight increase in strength in the stained wood. A second series of samples was, therefore, prepared and cultured. The technique followed was the same as that used in the first series; twentythree samples were used for static bending, and twenty-four for toughness. The average figures for the two series are given in Tables 1 and 2 . It will be seen that sterilization caused a reduction of all strength properties; but in this study the pertinent comparison is between the sterilized inoculated sticks and their sterilized controls, since for these the only variable was the presence of the brown-staining fungus. Some variation was found in the strength properties of the matched groups, but the average figures reveal very slight difference between the stained sticks and their sterilized controls. A mathematical examination of the results showed that the effect of brown stain on mechanical properties is negligible; it did show, however, a significant lowering of specific gravity.

A microscopic study of the stained wood showed that the fungus develops in the ray parenchyma, often entirely destroying the cells and consuming the food reserves. No bore-holes were found in the walls of the fibres, passage through these walls being in all cases through natural openings; this doubtless is the reason that the fungus does not affect the strength of the wood.

The moisture content of the stained sticks (Table 1 \& 2) was lower than that of the controls. This is contrary to observations of men in the field, who report that stained wood is wetter than that not penetrated by the fungus. It was, however, noted that as the fungus grew on the sticks in culture there was heavy condensation of water on the inner walls of the tubes; it was evident that the fungus was producing water in the breakdown of its food substances. In culture, owing to the large surface area of the wood samples in proportion to the area of the cross section, the water passed out of the wood; in a $\log$, this water would be unable to escape and would be trapped either in the stained wood or in adjacent tissues. It is to be expected that this excess of moisture might, by keeping the wood damp, increase or prolong its susceptibility to attack by decayproducing fungi.

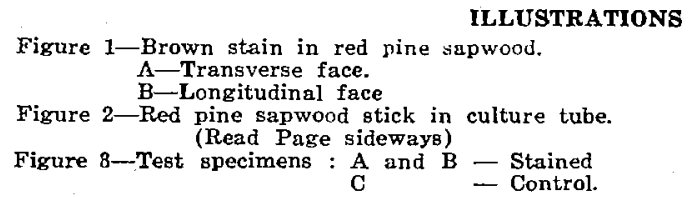



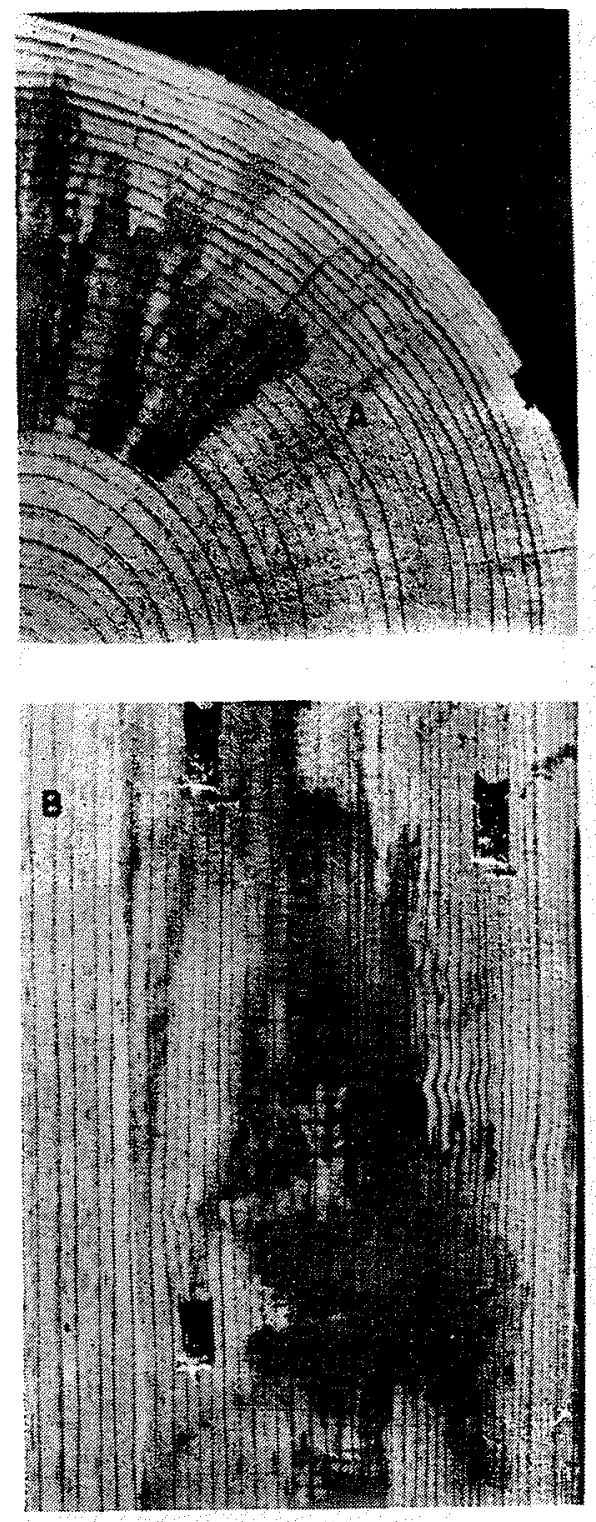

FICTR 1

Wotre 2
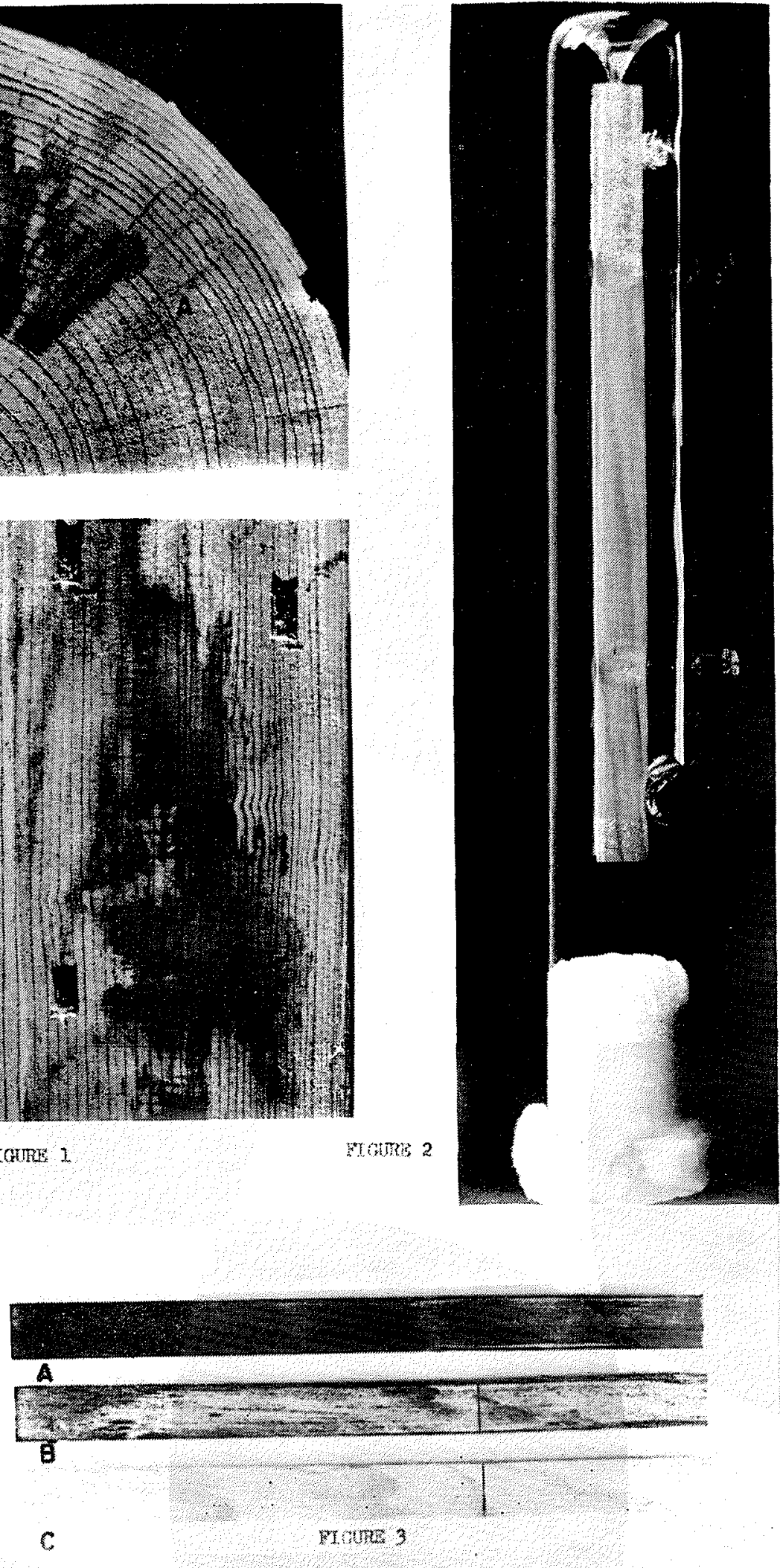
Table 1

Static Bending

(Average figures)

\begin{tabular}{|c|c|c|c|c|c|c|c|}
\hline Series & Condition & $\begin{array}{l}\text { No. of } \\
\text { Samples }\end{array}$ & $\underset{\%}{\text { M.C. }}$ & $\begin{array}{c}\text { Sp. Gr. } \\
\text { (Vol. at test } \\
\text { Wt. oven-dry) }\end{array}$ & $\begin{array}{l}\text { Fibre } \\
\text { at propo } \\
\text { limit }\end{array}$ & $\begin{array}{l}\text { Stress } \\
\text { ortionalM. of.R } \\
\text { p. s. i. p. s. i. }\end{array}$ & $\begin{array}{l}\text { M. of E. } \\
\text { R. } 1000 \\
\text { D. s. i. }\end{array}$ \\
\hline \multirow[t]{3}{*}{1} & Green control & 29 & 107.4 & .439 & 3360 & 6200 & 812 \\
\hline & Sterilized control & 29 & 70.1 & .434 & 2870 & 5590 & 733 \\
\hline & Stained sample & 29 & 63.9 & .417 & 2960 & 5750 & 740 \\
\hline \multirow[t]{3}{*}{2} & Green control & 23 & 172.4 & .406 & 2670 & 5870 & 1051 \\
\hline & Sterilized control ........... & 23 & 84.2 & .423 & 2100 & 5420 & 1016 \\
\hline & Stained sample ........... & 23 & 72.1 & .386 & 2270 & 5420 & 963 \\
\hline
\end{tabular}

Table 2

Toughness

(Average figures)

\begin{tabular}{|c|c|c|c|c|c|c|c|c|c|c|}
\hline Condition & $\begin{array}{l}\text { No. of } \\
\text { Samples }\end{array}$ & $\underset{\%}{\text { M.C. }}$ & - $\begin{array}{c}\text { (v } \\
\text { wt. }\end{array}$ & $\begin{array}{l}\text { Sp. Gr. } \\
\text { Vol. at test } \\
\text { oven-dry) }\end{array}$ & $\begin{array}{l}\text { Toughness } \\
\text { Inch-lbs. }\end{array}$ & $\begin{array}{l}\text { No. of } \\
\text { Samples }\end{array}$ & $\underset{\%}{\text { M.C. }}$ & Wt. & $\begin{array}{l}\text { Sp. Gr. } \\
\text { ol. at test } \\
\text { - oven-dry) }\end{array}$ & $\begin{array}{l}\text { Toughness } \\
\text { Inch-lbs. }\end{array}$ \\
\hline Green control & 23 & & 122.5 & .424 & 464.6 & 24 & & 74.1 & .412 & 261 \\
\hline Sterilized control & 23 & & 74.9 & .425 & 414.9 & 24 & & 88.1 & .412 & 252 \\
\hline Stained sample & 23 & & 59.3 & .408 & 438.9 & 24 & & 61.4 & .390 & 253 \\
\hline
\end{tabular}

\section{Effect on Strength}

\section{WOOD-ROT FUNGI}

Of the other fungi isolated from the poles, five belonging to the group which includes most of the wood-rot fungi, were grown in pure culture on blocks of wood. The loss in weight caused by their activity was determined. One of these, identified as Peniophora gigantea, caused a loss in weight of approximately $60 \%$ in three months; a second reduced the weight by $30 \%$; the remaining three were less active, causing a reduction of $5 \%$ to $11 \%$.

The effect of Peniophora gigantea on the strength of southern yellow pine sapwood was determined by Richards" in 1940 . She reported that; "... in six months Peniophora gigantea reduced fibre stress at proportional limit, modulus of rupture, work to proportional limit, and work to maximum load of loblolly pine by $20 \%$ or more," and that, "the greatest average reduction caused by $P$. gigantea was $35 \%$ in work to maximum load in slash pine specimens infected for six months." With this information available it was decided to use for strength tests the fungus which in preliminary work carried out by the writer had caused a $30 \%$ loss in weight. This fungus has not yet been identified and is designated B178.

Sticks of green red pine sapwood, $2 \mathrm{~cm} . \times 2 \mathrm{~cm} . \times 32 \mathrm{~cm}$., were prepared for static bending and toughness tests, and inoculated with suspensions of B178, using the technique described above for the brown stain study.

3 Richards, C.A., "The effect of Peniophora gigantea and Schizophyllum commune on strength of southern yellow nine sapwood." Proc. Am. Wood-Preservers" Ass'n. Jan. 1940. 
Twenty-eight specimens, with corresponding end-matched controls, were used for each test. The cultures were incubated for fourteen weeks.

The results showed that rot caused by B178 lowered the specific gravity of the wood and reduced all the strength properties tested. The average percentage reductions were: specific gravity, $10 \%$; fibre stress at proportional limit, $24 \%$; modulus of rupture, $18 \%$; modulus of elasticity, $13 \%$; and toughness, $53 \%$.

\section{CONCLUSIONS}

If pine logs or poles are held in storage under warm, humid conditions, sapwood stains develop quickly. The common chocolate-brown stain is so conspicuous that it has been considered as a serious defect, and likely to cause marked reduction in strength. The present study shows that brown stain does not itself reduce the strength of wood; its intensity and distribution cannot, therefore, be used as a basis for acceptance or rejection of poles.

Other fungi, however, may infect sapwood under the same conditions as those which favour the development of brown stain. Tests have shown that some of these cause a very serious reduction in strength properties.

The presence of sapwood stain, whether brown or blue, should act as a warning that the wood has been held under conditions which favour fungal growth. It is, therefore, inadvisable-owing to the possible presence of wood-rotting fungi-to use stained wood where maximum strength is required. 